Relations industrielles

Industrial Relations

\title{
Profit-Sharing for Small Business, JEHRING, J.J., 1 broch. 53 pp. Profit Sharing Foundation, Evanston, 1955.
}

\section{Gérard Dion}

Volume 11, numéro 2, mars 1956

URI : https://id.erudit.org/iderudit/1022649ar

DOI : https://doi.org/10.7202/1022649ar

Aller au sommaire du numéro

Éditeur(s)

Département des relations industrielles de l'Université Laval

ISSN

0034-379X (imprimé)

1703-8138 (numérique)

Découvrir la revue

Citer ce compte rendu

Dion, G. (1956). Compte rendu de [Profit-Sharing for Small Business, JEHRING, J.J., 1 broch. 53 pp. Profit Sharing Foundation, Evanston, 1955.] Relations industrielles / Industrial Relations, 11(2), 122-122.

https://doi.org/10.7202/1022649ar

Tous droits réservés (C Département des relations industrielles de l’Université Laval, 1956
Ce document est protégé par la loi sur le droit d'auteur. L’utilisation des services d'Érudit (y compris la reproduction) est assujettie à sa politique d'utilisation que vous pouvez consulter en ligne.

https://apropos.erudit.org/fr/usagers/politique-dutilisation/ 


\section{LIVRES ET REVUES}

JEHRING, J.J., Profit-Sharing for Small Business, 1 broch. 53 pp. Profit Sharing Foundation, Evanston, 1955.

Cette brochure préparée pour le compte d'une institution cherchant à promouvoir la participation aux bénéfices n'a pas un caractère de propagande. L'auteur a voulu présenter aux dirigeants de petites entreprises, (cent employés et moins) qui sont déjà intéressés à ces plans des explications claires concernant les buts et modalités d'application. Il a tiré ses illustrations d'une enquête menée par la Fondation auprès de 78 petites entreprises ayant expérimenté un plan de participation soit immédiate ou différée. Ce n'est pas une étude scientifique, mais elle est très pratique pour quiconque veut avoir une idée de la participation aux bénéfices dans les petites entreprises.

G. D.

ORNATI, OscaR, Jobs and Workers in India, The Institute of International Industrial and Labor Relations, Cornell University, Ithaca, N.Y., I vol., 215 pp. Price, paper $\$ 3.00$, Cloth $\$ 4.00$.

L'Inde est dans le monde oriental un pays qui occupe une place stratégique. Par sa situation géographique, par sa population - qui comprend le sixième de celle du globe - par l'orientation de sa politique, elle est apelée à jouer un rôle très important dans l'expansion du communisme. Nous n'avons pas le droit de nous montrer indifférents à ce qui s'y passe. L'ouvrage du professeur ORNATI veut être une initiation à une partie des problèmes qui s'agitent aux Indes. Il a choisi de parler du monde du travail et spécialement du travail industriel. Dans quelques chapitres, il donne une vue panoramique de la population, de la main-d'oeuvre et de l'emploi, de l'avènement de l'industrie, du régime de travail et des salaires et de la législation du travail. Il fait aussi une brève histoire du mouvement ouvrier et décrit les groupements actuellement existants. Enfin il analyse les pratiques courantes dans l'aménagement des rela- tions du travail: négociations collectives, le règlement des différends industriels.

Avec une population de plus de 350 millions d'habitants, l'Inde n'a que 7 millions de travailleurs industriels. Cependant la production par tête de ces travailleurs dépasse grandement celle des autres catégories sociales. En outre, grâce à leurs organisations syndicales, ils ont dans leur pays une influence beaucoup plus considérable que ne l'indique leur chiffre numérique. Par contre, à cause de l'industrialisation assez récente, de la mobilité des travailleurs, du tempérament propre aux habitants du pays, et pour une grande part, à cause de l'incurie des employeurs à rénover leurs techniques de production et leurs conceptions des rapports humains dans l'entreprise, le monde ouvrier est inadapté à sa nouvelle condition. Tous employeurs et salariés ont tendance à s'en remettre à l'Etat pour règler leurs problèmes. Et cela se situe à l'intérieur d'une économie où, à la fois il y a une sous-production et un chômage grandissant.

Il était impossible pour l'auteur de traiter à fond tous les problèmes qu'il a abordés. Cependant son étude a le mérite de mettre entre les mains du lecteur une synthèse et d'attirer son attention sur la nécessité d'un réaménagement des ressources humaines de ce pays. Ce sera le travail de spécialistes. L'ouvrage contient un appendice très précieux dans lequel l'auteur a préparé une bibliographie des principaux volumes publiés sur l'Inde.

\section{GÉrard Dion}

ROSEN, HJalmar and R. A. Hudson Rosen, The Union Member Speaks. New York: Prentice-Hall, Inc., 1955, $250 \mathrm{pp}$.

Voici la plus récente des études fort patientes qui ont été menées, ces dernières années, sur les opinions des membres locaux. Ces études sont venues sur le tard, et se comptent presque sur les doigts des deux mains. Mentionnons celles du R.P. Theodore V. Purcell, s.j., The Worker Speaks His Mind on Company and Union (Cambridge: Harvard University Press, 1953); d'Arnold Rose, Union Solidarity (Minneapolis: University of Minnesota Press, 1952); de Leo- 